\title{
Editorial
}

\section{Discovery of Artemisinin (Qinghaosu)}

\section{Fulong Liao}

Institute of Chinese Materia Medica, China Academy of Chinese Medical Sciences, Beijing, 100700, China; E-Mail: liaofulong100@yahoo.com.cn

Received: 9 December 2009 / Accepted: 18 December 2009 / Published: 21 December 2009

Artemisinin (Qinghaosu), a new antimalarial drug, was discovered in China in the early 1970s. The discovery of artemisinin is attributed to $\mathrm{You}-\mathrm{You} \mathrm{Tu}$, at that time a middle-aged phytochemist working in the Institute of Chinese Materia Medica, China Academy of Traditional Chinese Medicine. The following paragraph provides a brief summary of her discovery.

In the late 1960s and 1970s, Tu was the head of an antimalarial research group, which comprised both phytochemical and pharmacological researchers. She led her group of young scholars in the extraction and isolation of constituents with possible antimalarial activities from Chinese herbs. During the first stage of this research, her group investigated more than 2,000 Chinese herb preparations and identified 640 recipes that might have some antimalarial activities. More than 380 extracts, obtained from some 200 Chinese herbs, and including extracts from Artemisia annua L., were tested against a rodent malaria model. However, progress was not smooth and no significant results were obtained at first. The turning point came when an Artemisia extract showed a promising degree of inhibition against parasite growth, consistent with activity which had been reported for this species in "A Handbook of Prescriptions for Emergencies" by Ge Hong (Jin Dynasty, 284-346 AD). Tu brilliantly modified the extraction technique to perform it at low temperature, rather than using heating, as was conventional. Much better antimalarial activity was obtained after switching to the lower temperature procedure, and she found that the most effective preparation came from the leaves of Artemisia annua L., as evidenced by its significant inhibition of mouse malaria P. berghei. Unfortunately, this extract also appeared to be toxic to the animals, despite its effectiveness against malaria. However, $\mathrm{Tu}$ was able to separate the extract into an acidic portion, which contained no antimalarial activity, and a neutral extract, which exhibited both reduced toxicity and improved antimalarial activity. During the Cultural Revolution, there were no facilities for performing trials of new drugs, so, in order to help malaria sufferers, Tu and her colleagues bravely acted as the first group of volunteers and took the new extract themselves. After their first human experiments, Tu and her team went to Hainan to verify the efficacy of the extract clinically, and carried out antimalarial trails with patients infected with both $P$. vivax and $P$. falciparum. These clinical trials produced encouraging 
feedback, achieving a rapid disappearance of fever and parasites from the blood as compared with the control group using chloroquine. Tu next investigated the isolation and purification of the active component from Artemisia annua L. Eventually, in 1972, her team identified a colourless crystalline substance with a molecular weight of $282 \mathrm{Da}$, a molecular formula of $\mathrm{C}_{15} \mathrm{H}_{22} \mathrm{O}_{5}$ and a melting point of $156-157{ }^{\circ} \mathrm{C}$, as the active principal and named it "Qinghaosu" ("Qinghao" is the Chinese name of Artemisia annua L., and "su" means basic element). The stereochemistry and structure of Qinghaosu, was later determined by $\mathrm{Tu}$ in 1975 with the assistance of the Institute of Biophysics, Chinese Academy of Sciences, as that of a sesquiterpene lactone. The structure was first published in 1977 [2], and both the new molecule and the paper were quickly cited by Chemical Abstracts in the same year (C.A. 1977, 87, 98788g). However, because of the prevailing environment, not many papers concerning Qinghaosu were published and these were mostly in Chinese. In addition, authors were not always identified individually in some of the early papers [1-35], which is perhaps why the name of You-You Tu is not as well known internationally as that of her discovery, Qinghaosu.

Plasmodium falciparum has been a life-threatening disease for thousands of years and still threatens millions of lives every year in many parts of the World, particularly in Africa. After a failed international attempt to eradicate malaria in the $1950 \mathrm{~s}$, the disease rebounded, largely due to the emergence of parasites which were resistant to the existing antimalarial drugs of the time, such as chloroquine. Artemisinin was a new antimalarial agent with a totally different chemical structure and a higher efficacy, as compared with the conventional drugs against which resistance has been acquired and the successful application of Qinghaosu (artemisinin) and its derivatives for treating several thousand malaria patients in China attracted worldwide attention in the 1980s [36]. The discovery of artemisinin has since been recognized as a significant milestone in the human journey towards conquering malaria. In 2005, WHO announced a switch in strategy to artemisinin combination therapy (ACT). ACT is currently widely used, saving many lives, mostly of children in Africa (the remedy impressively reduces the intensity of malaria in Africa due to its anti-gametocyte activity). None of this could have been achieved without the initial discovery of Qinghaosu.

Qinghaosu was awarded the status of "national scientific discovery" by the Committee of Science and Technology of China in 1979. During a special program for research and training in tropical diseases of the fourth meeting of the scientific working group on the chemotherapy of malaria (sponsored by UNDP/World Bank/WHO) in Beijing in 1981, Prof. Tu was invited to deliver a lecture on Qinghaosu. Chinese new drug certificates were issued both for Qinghaosu and for its derivatives which had been developed by Prof. Tu and her team [36-40]. Since the 1970s, Qinghaosu and Prof. You-You Tu have won more than ten awards at a national level in China [43-55]. Prof. Tu is now the director of the Qinghaosu Research Center, Institute of Chinese Materia Medica, China Academy of Chinese Medical Sciences (the renamed China Academy of Traditional Chinese Medicine), and a life-long professor of the academy. On the occasion of Prof. You-You Tu's 80th Anniversary, we would like to express our cordial respect to the discoverer of artemisinin (Qinghaosu), the great master playing with molecular diversity, for her outstanding contribution to the mankind. 


\section{References and Notes}

1. Department of Chemistry. Chemical studies on Artemisia annua L. Research Data and References on Chinese Materia Medica (in Chinese). A nonscheduled publication by the Institutite of Chinese Materia Medica; the special issue collected research progresses on studies of Artemisia annua L. from 1971 to 1978 achieved by the institute, 1978, 3, 35-56.

2. Collaboration research group for Qinghaosu. A new sesquiterpene lactone-Qinghaosu (in Chinese). Kexue Tongbao 1977, 3, 142.

3. Liu, J.; Ni, M., Fan, J.; Tu, Y. Wu, Z.; Wu, Y.; Zhou, W. Structure and reaction of Qinghaosu (in Chinese). Acta Chim. Sinica 1979, 37, 129-143.

4. Collaboration research group for Qinghaosu. Studies on new anti-malarial drug Qinghaosu (in Chinese). Yaoxue Tongbao 1979, 14, 49-53.

5. Collaboration research group for Qinghaosu. Antimalarial studies on Qinghaosu (in Chinese). Chin. Med. J. 1979, 92, 811-816

6. Tu, Y. The awarded Chinese invention: Antimalarial drug Qinghaosu (in Chinese). Rev. World Invent. 1981, 1, 6.

7. Tu, Y.; Ni, M.; Zhong, Y.; Li, L.; Cui, S.; Zhang, M.; Wang, X.; Liang, X. Studies on the constituents of Artemisia annua L (in Chinese). Yao Xue Xue Bao 1981, 16, 366 - 368.

8. Tu, Y.; Ni, M.; Zhong, Y.; Li, L. Studies on the constituents of Artemisia annua L. and derivatives of artemisinin (in Chinese). Zhongguo Zhong Yao Za Zhi 1981, 6, 31 - 32.

9. Tu, Y.; Ni, M.; Zhong, Y.; Li, L.; Cui, S.; Zhang, M.; Wang, X.; Ji, Z.; Liang, X. Studies on the constituents of Artemisia annua L.(II). Planta Med. 1982, 44, 143-145.

10. Collaboration research group for Qinghaosu. Chemical studies on Qinghaosu. J. Tradit. Chin. Med. 1982, 2 (1), 3-8.

11. Xiao, Y.; Tu, Y. Isolation and identification of the lipophilic constituents from Artemisia anomala S. Moore (in Chinese). Yaо Хие Хие Bao 1984, 19, 909-913.

12. Tu, Y.; Yin, J.; Ji, L.; Huang, M.; Liang, X. Studies on the constituents of Artemisia annua L. (III) (in Chinese). Chin. Tradit. Herbal Drugs 1985, 16, 200-201.

13. Wu, C.; Tu, Y. Studies on the constituents of Artemisia apiacea Honce (in Chinese). Chin. Tradit. Herbal Drugs 1985, 6, 2-3.

14. Tu, Y. Zhu, Q.; Shen, X. Studies on the constituents of Young Artemisia annua L. (in Chinese). Zhongguo Zhong Yao Za Zhi 1985, 10, 419-420.

15. Wu, C.; Tu, Y. Studies on the constituents of Artemisia gmelinii Web.exstechm (in Chinese). Chin. Bull. Bot. 1985, 8, 34-35.

16. Wu, C.; Tu, Y. Studies on the constituents of Artemisia argyi Levl et vant (in Chinese). Zhongguo Zhong Yao Za Zhi 1985, 10, 31-32.

17. Xiao, Y.; Tu, Y. Isolation and identification of the lipophilic constituents from Artemisia anomala S. Moore (in Chinese). Acta Bot. Sinica 1986, 28, 307-310.

18. Tu, Y. To inherit and to develop the heritage of traditional Chinese medicine for the honor of the motherland (in Chinese). Zhongguo Zhong Xi Yi Jie He Za Zhi 1986, 6, 174 - 176.

19. Tu, Y. Study on authentic species of Chinese herbal drug Qinghao (in Chinese). Bull. Chin. Mater.Med.1987, 12, 2-5. 
20. Yin, J.; Tu, Y. Studies on the constituents of Artemisia eriopoda Bunge (in Chinese). Chin. Tradit. Herbal Drugs 1989, 20, 149-150.

21. Gu, Y.; Tu, Y. Studies on Chemical Constituents of Artemisia japonica Thunb (in Chinese). Chin. Tradit. Herbal Drugs 1993, 24, 122-124.

22. Sun, X.; Xie, S.; Long, Z.; Zhang, Z.; Tu, Y. Experimental study on the immunosuppressive effects of Qinghaosu and its derivatives (in Chinese). Zhongguo Zhong Xi Yi Jie He Za Zhi 1991, 11, 37-38.

23. Yang, S.; Xie, S.; Ma, D.; Long, Z.; Tu, Y. Immunologic enhancement and reconstitution by Qinghaosu and its derivatives (in Chinese). Chin. Bull. Pharm. 1992, 9, 61-63.

24. Chen, P. ; Tu, Y.; Wang, F. ; Li, F. ; Yang, Lan. Effect of DihydroQinghaosu on the Development of Plasmodium Yoelii in Anopheles Stephensi (in Chinese). Ji Sheng Chong Xue Yu Ji Sheng Chong Bing Za Zhi 1998, 16, 421- 424.

25. Huang, L.; Liu, J.; Liu, L.; Li, D.; Zhang, Y.; Nui, H.; Song, H.; Zhang, C.; Liu, X.; Tu, Y. Studies on the Antipyretic and Anti-inflammatory Effects of Artemisia annua L (in Chinese). Zhongguo Zhong Yao Za Zhi 1993, 18, 44-48.

26. Tu, Y. The development of new antimalarial drugs: Qinghaosu and Dihydro-Qinghaosu. Chin. Med. J. 1999, 112, 976-977.

27. Xu, L.; Chen, X.; Tu, Y. Effect of Hydroartemisinin on Lupus BXSB Mice (in Chinese). Chin. J. Dermatovenerol. Integr. Tradit. West. Med. 2002, 1, 19-20.

28. Dong, Y.; Li, W.; Tu, Y. Effect of Dihydro-Qinghaosu on Auto-antibody Production, TNFa Secretion and Pathologic Change of Lupus Nephritis in BXSB Mice (in Chinese). Zhongguo Zhong Xi Yi Jie He Za Zhi 2003, 23, 676-679.

29. Dong, Y.; Li, W.; Tu, Y.; Zhang, H.; Zou, W.; Yang, L.; Lin, Z. The effects of DQHS on the pathologic changes in BXSB mice lupus nephritis and the effect mechanism (in Chinese). Chin. Pharmacol. Bull. 2003, 19, 1125-1128.

30. Tu, Y. The development of the antimalarial drugs with new type of chemical structure: Qinghaosu and DihydroQinghaosu. Southeast Asian J. Trop. Med. Public Health 2004, 35, 250-251.

31. Tu, Y. The journey of antimalarial drug-Qinghaosu. In A Collection of Memories for the Fifty Years (1955-2005) of the Institute of Chinese Materia Medica (in Chinese); Institute of Chinese Materia Medica, China Academy of Chinese Medical Sciences: Beijing, China; pp. 4-10.

32. Yang, L.; Wang, M.; Zhang, D.; Tu, Y. Determination of Scopoletin in Qinghao by HPLC (in Chinese). Chin. J. Exp. Tradit. Med. Formulae 2006, 12, 10-11.

33. Li, W.; Dong, Y.; Tu, Y.; Lin, Z. Dihydroarteannuin ameliorates lupus symptom of BXSB mice by inhibiting production of TNF-alpha and blocking the signaling pathway NF-kappa B translocation. Int. Immunopharmacol. 2006, 6, 1243-1250.

34. Zhang, D.; Yang, L.; Yang, L.; Wang, M.; Tu, Y. Determination of artemisinin, arteannuin B and artemisinic acid in Artemisia Annua by HPLC-UV-ELSD (in Chinese). Yao Хие Хие Вaо 2007, 42, 978-981.

35. Tu, Y., Ed. Qinghao Ji Qinghaosulei Yaowu (Artemisia annua L., Artemisinin and Its Alikes) (in Chinese); Publisher of Chemical Industry: Beijing, China, 2009.

36. Klayman, D.L. Qinghaosu (artemisinin): An antimalarial drug from China. Science 1985, 228, 1049-1055 
37. New Drug Certificate (86 X-01) for Qinghaosu, issued by the Ministry of Health, China.

38. New Drug Certicicate $(92$ X66,67) for Dihydro-Qinghaosu issued by the Ministry of Health.

39. New Drug Certicicate (H20030344) for Qinghaosu Tablet issued by State Food \& Drug Administration (SFDA).

40. New Drug Certicicate (H20030341) for Suppositories of Dihydro-Qinghaosu issued by SFDA.

41. Antimalarial New Drug-Compound Recipe of Dihydro-Qinghaosu. Chin. Pat. Invent. ZL99109669.X, 2004.

42. Drugs Containing Dihydro-Qinghaosu for Treatment of Lupus Erythematosus and Photoallergic Diseases. Chin. Pat. Invent. ZL99103346.9, 2004.

43. Clinical Approval of Dihydro-Qinghaosu for Treatment of Lupus Erythematosus (2004L02089) issued by SFDA, June 2004.

44. Award for progress in anti-malarial research achieved by "Project 523" Scientific Team, by National Congress of Science and Technology, 1978

45. National Scientific Discovery Award for Antimalaria Drug-Qinghaosu, by the Committee of Science and Technology, China, 1979.

46. Invention Award ( $\mathrm{Tu}$ as the first inventor), by National Congress for Awards in Science and Technology, 1982.

47. Young and Middle-aged Experts with Outstanding Contribution, by National Ministry of Personnel, 1984.

48. Dihydro-Qinghaosu and its Tablet were awarded as the Top Ten National Achievements for Progress in Science and Technology by National Committee of Science and Technology in 1992.

49. Quality Studies on commonly used Chinese Matria Medica (Artemisia annua L. is one of them), First-rate Award of National Achievements in Science and Technology, National Award Committee for Advances in Science and Technology, 1992.

50. National Model Worker, by the State Council, 1995.

51. Award for Outstanding Achievement in Traditional Chinese Medicine, by Guangzhou Zhongjing Award Foundation for Traditional Chinese Medicine, 1995.

52. Outstanding Scientific Achievement Award, by Qiu Shi Science and Technologies Foundation of Hong Kong, 1996.

53. Dihydro-Qinghaosu and its Tablet was awarded as the Top Ten Health Achievements in New China, by Ministry of Health in 1997.

54. Woman Inventor of the New Century, by National Bureau of Intellectual Property, 2002.

55. Golden Medal of the $14^{\text {th }}$ National Invention Exhibition, by National Bureau of Intellectual Property, 2003.

56. Award for Development of Chinese Materia Medica, Cyrus Chung Ying Tang Foundation, 2009.

(C) 2009 by the authors; licensee Molecular Diversity Preservation International, Basel, Switzerland. This article is an open-access article distributed under the terms and conditions of the Creative Commons Attribution license (http://creativecommons.org/licenses/by/3.0/). 